\title{
Evaluation of the Relation between Vitamin D and Serum Omentin and Vaspin Levels in Women
}

\author{
Authors \\ M. Zorlu' , M. Kiskac ${ }^{1}$, M. Cakirca ${ }^{1}$, C. Karatoprak ${ }^{1}$, E. M. Güler ${ }^{2}$, K. Çelik ${ }^{1}$, i. Gültepe ${ }^{1}$, M. A. Cikrikcioglu ${ }^{1}$, \\ A. Kocyigit \\ Affiliations \\ ${ }^{1}$ Internal Medicine Clinic, Bezmialem Vakif University, Faculty of Medicine, Fatih, Istanbul, Turkey \\ ${ }^{2}$ Deparment of Medical Biochemistry, Bezmialem Vakif University, Faculty of Medicine, Fatih, Istanbul, Turkey
}

Key words
omentin
vaspin
vitamin D

received 04.02.2016

first decision 05.05.2016

accepted $\quad$ 19.05.2016

Bibliography

DOI http://dx.doi.org/

10.1055/s-0042-108853

Exp Clin Endocrinol Diabetes 2016; 124: 440-443

(C) . A. Barth Verlag in

Georg Thieme Verlag KG

Stuttgart · New York

ISSN 0947-7349

Correspondence

M. Zorlu, MD

Internal Medicine Clinic

Bezmialem Vakif University

Faculty of Medicine

34093 Fatih

Istanbul

Turkey

Tel.: + 90/212/45317006506

Mobile: + 90/505 5944375

drmehmetzorlu@mynet.com

\section{Abstract \\ $\nabla$}

Introduction: Vitamin D deficiency is a common health problem seen worldwide. Adipokines released from adipose tissue play important roles in the control of appetite and satiety, modulation of body fat distribution, regulation of insulin sensitivity and secretion, control of blood pressure, and regulation of endothelial functions and inflammation. The aim of the present study is to investigate how vitamin D levels affect serum vaspin and omentin levels.

Materials and methods: This is a cross-sectional study design. A total of 77 female volunteers were included in the study, and they were divided into 3 groups according to vitamin D levels. Relation of vitamin D with serum vaspin and omentin levels was determined in these groups. Results: Serum omentin, vaspin and parathyroid hormone (PTH) levels differed significantly between the groups $(\mathrm{p}<0.001, \mathrm{p}<0.001$, $\mathrm{p}=0.001$, respectively). Omentin levels cor-

\section{Introduction}

$\nabla$

Vitamin D deficiency is a common health problem seen worldwide. Vitamin D was previously considered to be mainly effective on calcium and bone metabolism; however it is currently understood that this vitamin is related with various systems and diseases. Vitamin D has been shown to be related with obesity, cardiometabolic diseases, impaired glucose tolerance, diabetes mellitus, metabolic syndrome, and hypertension. Relation between vitamin D and insulin levels have been shown in many studies [1,2]. Adipokines released from adipose tissue play important roles in the control of appetite and satiety, modulation of body fat distribution, regulation of insulin sensitivity and secretion, maintenance of body energy balance, control of blood pressure, and regulation of endothelial functions and related significantly and negatively with the vitamin $\mathrm{D}$ and vaspin levels, but there was a significant positive correlation between omentin and PTH $(r=-0.626, p<0.001 ; r=-0.867$, $\mathrm{p}<0.001 ; \mathrm{r}=0.461, \mathrm{P}<0.001$, respectively). A significant positive correlation was detected between vaspin levels and vitamin $\mathrm{D}$, whereas omentin and PTH levels correlated negatively and significantly $(\mathrm{r}=0.374, \mathrm{p}<0.001 ; \mathrm{r}=-0.867$, $\mathrm{p}<0.001 ; \mathrm{r}=-0.374, \mathrm{p}=0.002$, respectively).

Conclusions: Vitamin D may affect the release of adipokines from the adipose tissue, and this effect may be in a negative or positive manner. This effect of vitamin D may probably be mediated via vitamin $\mathrm{D}$ receptors exhibited in the adipose tissue, or via mechanisms not identified yet. The results of this study suggested that there was a significant, positive correlation between serum vitamin D levels and vaspin, whereas a significant, negative correlation between vitamin D levels and omentin. Further studies on larger series are needed in order to confirm these results.

inflammation $[3,4]$. Additionally via their autocrine and paracrine effects, adipokines contribute to the regulation of adipogenesis, migration of immune cells into the adipose tissue, and modulation of adipocyte metabolism and functions $[3,5]$.

Vaspin (visceral adipose tissue-derived serpin) is a member of this adipocytokine family. A serine protease inhibitor, vaspin is an insulin-sensitizing adipocytokine. An increase in serum vaspin levels was suggested to be a compensatory response to antagonize the activity of the proteases expressed in insulin resistance and obesity. In other words, a high vaspin level has a defensive effect against insulin resistance [6]. Omentin is an adiponectin primarily produced by the visceral adipose tissue, and it has insulinsensitizing effects. Omentin release decreases in obesity, type 2 diabetes mellitus, and in insulin 
resistance. It is positively correlated with high-density lipoprotein cholesterol (HDL-C), whereas inversely correlated with body mass index (BMI), waist circumference, insulin resistance and triglyceride. Decreased plasma omentin levels contribute to the pathogenesis of insulin resistance, type 2 diabetes mellitus and cardiovascular diseases. Omentin possesses anti-inflammatory, antiatherogenic, anti-cardiovascular disease and antidiabetic properties [7].

Vitamin D has multifactorial effects, and some of its effects are also exerted on the adipose tissue. Therefore changes in vitamin D levels may affect the levels of adipokines released from the adipose tissue [8]. We consider that vitamin D may exert some of its systemic effects indirectly, via these adipokines. We could not reach a study in the literature evaluating the relation between vitamin $\mathrm{D}$, and the adipokines vaspin and omentin. We therefore aimed in this study to investigate the relation between vitamin D levels, and the levels of serum vaspin and omentin.

\section{Materials and Methods}

$\nabla$

\section{Study group}

Female volunteers ( $n=77$ ) who attended the Bezmialem Foundation University, Internal Medicine Outpatient Clinic between november 2014 and february 2015, were included in the study. Study was performed after taking written confirmations of the participants, and the University Ethic Council. Women were divided into 3 groups by considering their vitamin D levels according to the vitamin $D$ reference interval of the university laboratory. Vitamin D levels of the groups were as follows: vitamin D 0-9.9 ng/mL (serious deficiency), $10-24.9 \mathrm{ng} / \mathrm{mL}$ (moderate deficiency), and $25-80 \mathrm{ng} / \mathrm{mL}$ (normal level). Cases possessing the followings were excluded from the study: malignity, diabetes mellitus (DM), chronic renal failure (CRF), chronic liver disease, psychiatric disorders, coronary and cerebrovascular diseases, pregnancy, abnormal thyroid function tests, disorders in calcium metabolism and treatment with drugs that affect vitamin D.

All volunteers underwent a thorough physical examination and their height, weight were recorded. Weight and height were measured to the nearest kilogram and centimeter, respectively, and BMI (body mass index) was calculated [BMI=weight/ (height $)^{2}$ ]

\section{Blood analysis}

After $12 \mathrm{~h}$ of fasting, venous blood samples were collected into the gelly tubes between 8:00 a.m. and 9:00 a.m. Samples were then centrifuged for $10 \mathrm{~min}$ at $3600 \mathrm{rpm}$, and sera were separated. Fasting glucose level, urea, creatinine, triglycerides, total cholesterol, low-density lipoprotein cholesterol (LDL-C), highdensity lipoprotein cholesterol (HDL-C), fasting serum insulin level, glycolytic hemoglobin (HbA1C), alanine aminotransferase (ALT), aspartate aminotransferase (AST), alkaline phosphatase (ALP), lactate dehydrogenase (LDH), calcium (Ca), phosphorus $(\mathrm{P})$, creatine kinase $(\mathrm{CK})$, iron, total iron binding capacity (TIBC), complete blood count, thyroid stimulating hormone (TSH), PTH and vitamin $\mathrm{D}(25-\mathrm{OH}$ Vitamin $\mathrm{D})$ were analyzed in all subjects. The homeostasis model assessment (HOMA) of insulin resistance index, a measure of insulin sensitivity, was calculated by multiplying fasting insulin concentration $(\mu \mathrm{U} / \mathrm{mL} \mathrm{U} / \mathrm{mL})$ by fasting glucose concentration $(\mathrm{mmol} / \mathrm{L}) / 22.5[9]$.
For omentin and vaspin analyses, sera were collected into eppendorf tubes, and were then stored at $-80^{\circ} \mathrm{C}$ till the assay day. On the assay day, samples were kept at room temperature, and omentin and vaspin were measured (Thermo analysator, Scientific Multiskan FC, USA) by using a commercial enzyme immunoassay kit (Aviscera Bioscience, Santa Clara, USA) according to the manufacturer's instructions. Samples were measured in duplicate, and the average was used in the data analysis.

\section{Statistical analysis}

SPSS (Statistical Package for Social Sciences) for Windows 20.0 software was used to perform the statistical analysis of the data. The continuous variables were expressed as the mean \pm standard deviation. Continuous variables were compared between the 2 groups using Mann-Whitney U test. Student's t-test was used to compare parametric variables between the patient and control groups and Chi-square test was used for categorical variables. Bivariate correlation analyses were done by Spearman's test. Vaspin and omentin values in 3 groups were compared by using one way ANOVA test. Post Hoc comparison was performed by LSD method. A p-value $<0.05$ was considered statistically significant.

\section{Results}

$\nabla$

Our study included female cases with serious $n=26$ (\%34) and moderate $n=26$ (\%34) vitamin $D$ deficiencies, and normal volunteers $n=25$ (\%32). A total of 77 women were evaluated. In our laboratory, a $25-\mathrm{OH}$ vitamin $\mathrm{D}$ level of $0-9.9 \mathrm{ng} / \mathrm{mL}$ is considered as serious deficiency, levels from 10 to $24.9 \mathrm{ng} / \mathrm{mL}$ are considered as moderate deficiency, levels between 25 and $80 \mathrm{ng} / \mathrm{mL}$ are considered as optimal and levels higher than $81 \mathrm{ng} / \mathrm{mL}$ are considered as possible toxicity. Cases were grouped with regard to vitamin D levels, as follows: group A (vitamin D $6.91 \pm 1.97 \mathrm{ng}$ / $\mathrm{mL}$ ), group B (vitamin D $14.99 \pm 3.80 \mathrm{ng} / \mathrm{mL}$ ), and group C (vita$\min \mathrm{D} 46.99 \pm 24.45 \mathrm{ng} / \mathrm{mL}$ ). These 3 groups did not show statistically significant differences with regard to age, body mass index (BMI), fasting blood glucose, creatinine, triglyceride, total cholesterol, HDL-C, LDL-C, Ca, P, HOMA-IR, and TSH values. However serum omentin, vaspin and PTH values differed significantly between the groups $(\mathrm{p}<0.001, \mathrm{p}<0.001, \mathrm{p}=0.001$, respectively) ( $\bullet$ Table $\mathbf{1}$ ).

Negative correlations determined between serum omentin levels and age, BMI, fasting blood glucose, total cholesterol, triglyceride, LDL-C, HDL-C, HbA1c, Ca and ALP values, were not significant statistically. Positive correlation between serum omentin levels and HOMA-IR, was also not significant statistically. However negative correlations between omentin levels, and vitamin $\mathrm{D}$ and vaspin values were found to be statistically significant. Positive correlation between omentin levels and PTH, was also significant statistically $(r=-0.626 ; p<0.001$, $\mathrm{r}=-0.867 ; \mathrm{p}<0.001, \mathrm{r}=0.461 ; \mathrm{p}<0.001$, respectively) ( $\odot$ Table 2). Positive correlations between serum vaspin levels and age, BMI, fasting blood glucose, total cholesterol, triglyceride, LDL-C, HDL$\mathrm{C}, \mathrm{HbA1c}, \mathrm{Ca}$ and ALP values were not significant statistically. Negative correlation between serum vaspin and HOMA-IR was also not significant statistically. However positive correlation between vaspin levels and vitamin $\mathrm{D}$, and negative correlations between vaspin levels and omentin and PTH values, were found to be statistically significant $(r=0.745 ; P<0.001, r=-0.867$; $\mathrm{P}<0.001, \mathrm{r}=-0.374 ; \mathrm{p}=0.002$, respectively ( $\odot$ Table 3 ). 
Table 1 Comparison of anthropometric and biochemical parameters of the groups with regard to vitamin D levels.

\begin{tabular}{|c|c|c|c|c|}
\hline & $\begin{array}{l}\text { Group A } \\
\text { patients }(n=26) \\
\text { Mean } \pm \text { SD }\end{array}$ & $\begin{array}{l}\text { GroupB } \\
\text { patients }(n=26) \\
\text { Mean } \pm \text { SD }\end{array}$ & $\begin{array}{l}\text { Grup C } \\
\text { Normal }(n=25) \\
\text { Mean } \pm \text { SD }\end{array}$ & $\mathbf{p}$ \\
\hline Age (years) & $38.42 \pm 12.63$ & $42.26 \pm 13.44$ & $46.04 \pm 10.84$ & 0.096 \\
\hline $\mathrm{BMI}\left(\mathrm{kg} / \mathrm{m}^{2}\right)$ & $26.62 \pm 5.37$ & $27.85 \pm 5.67$ & $28.54 \pm 5.26$ & 0.445 \\
\hline Omentin (ng/mL) & $97.80 \pm 7.77$ & $68.62 \pm 4.76$ & $55.96 \pm 3.39$ & $<0.001^{*}$ \\
\hline Vaspin (ng/mL) & $0.88 \pm 0.05$ & $1.21 \pm 0.10$ & $1.63 \pm 0.16$ & $<0.001^{*}$ \\
\hline Insulin (mU/L) & $11.74 \pm 6.94$ & $12.42 \pm 5.77$ & $10.98 \pm 4.97$ & 0.690 \\
\hline HOMA-IR & $2.70 \pm 1.92$ & $2.79 \pm 1.33$ & $2.63 \pm 1.09$ & 0.935 \\
\hline HbA1c (\%) & $5.43 \pm 0.39$ & $5.50 \pm 0.39$ & $5.51 \pm 0.41$ & 0.748 \\
\hline Fasting blood glucose (mg/dL) & $91.23 \pm 9.18$ & $92.08 \pm 10.06$ & $93.64 \pm 9.51$ & 0.664 \\
\hline Totalcholesterol (mg/dL) & $184.42 \pm 43.02$ & $200.00 \pm 63.59$ & $202.04 \pm 35.5$ & 0.380 \\
\hline Triglyceride (mg/dL) & $102.27 \pm 74.97$ & $108.92 \pm 71.63$ & $108.84 \pm 52.8$ & 0.920 \\
\hline LDL-C (mg/dL) & $109.92 \pm 29.93$ & $128.35 \pm 58.93$ & $133.32 \pm 31.2$ & 0.120 \\
\hline HDL-C (mg/dL) & $57.54 \pm 15.05$ & $55.64 \pm 12.73$ & $56.99 \pm 14.27$ & 0.849 \\
\hline $\operatorname{ALT}(\mathrm{U} / \mathrm{L})$ & $18.50 \pm 9.75$ & $18.92 \pm 6.41$ & $24.20 \pm 12.29$ & 0.07 \\
\hline CK (U/L) & $90.31 \pm 46.74$ & $89.50 \pm 45.21$ & $94.00 \pm 54.75$ & 0.94 \\
\hline $\operatorname{ALP}(U / L)$ & $70.35 \pm 17.21$ & $63.81 \pm 15.98$ & $73.84 \pm 21.06$ & 0.141 \\
\hline $\mathrm{Ca}(\mathrm{mg} / \mathrm{dL})$ & $9.36 \pm 0.35$ & $9.26 \pm 0.35$ & $9.40 \pm 0.35$ & 0.335 \\
\hline$P(\mathrm{mg} / \mathrm{dL})$ & $3.43 \pm 0.51$ & $3.58 \pm 0.55$ & $3.39 \pm 0.56$ & 0.417 \\
\hline TSH (ulu/ml) & $2.16 \pm 1.97$ & $2.09 \pm 1.20$ & $1.99 \pm 1.38$ & 0.929 \\
\hline PTH (pg/ml) & $68.54 \pm 18.75$ & $60.57 \pm 22.05$ & $45.63 \pm 14.29$ & $0.001^{*}$ \\
\hline
\end{tabular}

Table 2 Evaluation of correlations between serum omentin levels, and anthropometric and biochemical parameters in the volunteers.

\begin{tabular}{|lcc|}
\hline & $\mathbf{r}$ & p-Value \\
\hline Age & -0.224 & 0.050 \\
\hline BMI & -0.162 & 0.158 \\
\hline Fasting blood glucose & -0.053 & 0.646 \\
\hline Vaspin & -0.867 & $<0.001^{*}$ \\
\hline HbA1c & -0.039 & 0.738 \\
\hline Total cholesterol & -0.197 & 0.089 \\
\hline Triglyceride & -0.065 & 0.573 \\
\hline LDL-C & -0.287 & 0.895 \\
\hline HDL-C & -0.025 & 0.832 \\
\hline ALP & -0.008 & 0.946 \\
\hline Ca & -0.020 & 0.867 \\
\hline P & -0.021 & 0.854 \\
\hline PTH & 0.461 & $<0.001^{*}$ \\
\hline HOMA-IR & 0.031 & 0.794 \\
\hline Vitamin D & -0.626 & $<0.001^{*}$ \\
\hline BMI: body mass index, HbA1c: glycolytic hemoglobin, LDL-C: low-density lipo- \\
protein cholesterol, HDL-C: high-density lipoprotein cholesterol, ALP: alkaline \\
phosphatase, Ca: calcium, P: phosphorus, PTH: parathyroid hormone, HOMA-IR: \\
\hline homeostasis model assesment insuline resistance. ${ }^{*}$ statistical significance (p<0.05)
\end{tabular}

\section{Discussion}

In this study we aimed to determine serum omentin, vaspin and vitamin D levels in the volunteers, to evaluate correlations of these markers with the anthropometric, metabolic and biochemical parameters, and also to determine correlations of these markers with each other. In order to minimize influences of other factors, cases possessing similar demographic and anthropometric properties were included in the study. It is reported in various studies that vitamin D deficiency is more common in women than in men, and that women possess more severe forms of the disease. Women generally spend most of
Table 3 Evaluation of correlations between serum vaspin levels, and anthropometric and biochemical parameters in the volunteers.

\begin{tabular}{|lcc} 
& & \\
& $\mathbf{r}$ & P-Value \\
\hline Age & 0.253 & 0.026 \\
\hline BMI & 0.206 & 0.072 \\
\hline Fasting blood glucose & 0.171 & 0.137 \\
\hline Omentin & -0.867 & $<0.001^{*}$ \\
\hline HbA1c & 0.157 & 0.176 \\
\hline Total cholesterol & 0.124 & 0.286 \\
\hline Triglyceride & 0.047 & 0.686 \\
\hline LDL-C & 0.198 & 0.084 \\
\hline HDL-C & 0.008 & 0.943 \\
\hline ALP & 0.084 & 0.470 \\
\hline Ca & 0.051 & 0.663 \\
\hline P & -0.084 & 0.472 \\
\hline PTH & -0.374 & $0.002^{*}$ \\
\hline HOMA-IR & -0.030 & 0.799 \\
\hline Vitamin D & 0.745 & $<0.001^{*}$ \\
\hline BMI: body mass index, HbA1c: glycolytic hemoglobin, LDL-C: low-density lipo- & \\
\hline protein cholesterol, HDL-C: high-density lipoprotein cholesterol, ALP: alkaline \\
\hline phosphatase, Ca: calcium, P: phosphorus, PTH: parathyroid hormone, HOMA-IR: \\
\hline homeostasis model assessment insuline resistance. ${ }^{*}$ statistical significance (p<0.05) \\
\hline
\end{tabular}

their time for indoor activities, and thus they are not exposed to sunlight efficiently; this may be the reason of more common vitamin D deficiency reported in women in various studies [10$12]$.

In our study, vitamin D and vaspin levels correlated positively and significantly, whereas there was an inverse and significant relation between vitamin $\mathrm{D}$ and omentin values. We could not reach a study in the literature evaluating and comparing omentin and vaspin, which are adipokines, in the vitamin D-deficient patients and normal subjects. There are however studies investigating other adipokines and vitamin D levels in different disease states. Ulutaş et al. have compared before- and after-treatment 
leptin and adiponectin levels in vitamin D-deficient patients undergoing peritoneal dialysis [13]. In this study leptin levels significantly increased with increasing vitamin D levels, but no significant relation was determined between vitamin $\mathrm{D}$ and adiponectin. In a study by Maggi S et al., serum leptin levels were increased by vitamin $\mathrm{D}$ therapy in the type 2 diabetic patients [14]. Similarly, Gannage-Yared et al. reported relation of high vitamin D levels with high adiponectin values in the vitamin D-deficient, nonobese, young subjects $[13,15]$. Nimitphong et al. also showed positive correlation between vitamin $\mathrm{D}$ and adiponectin $[13,16]$. Adiponectin, which is a multifunctional protein, has protective effects for the followings: development of insulin resistance, dyslipidemia, nonalcoholic fatty liver, atherosclerosis, cardiac hypertrophy, and ischemic diseases $[13,17,18]$. Vitamin D may be positively correlated with some of the adipokines, and negatively correlated with the others, In our study, similarly, vaspin and vitamin D correlated positively, but omentin levels decreased when vitamin D levels increased. Preadipocytes were shown to possess vitamin D receptors $[13,19,20]$. Active form of vitamin $\mathrm{D}$ probably exerts different effects via different mechanisms (e.g., gene expression, and others) by acting through these receptors, and by affecting adipokines.

There are also studies indicating inverse relations of some adipokines with each other. For example in a study by Souza Batista et al., plasma omentin levels were negatively correlated with BMI, leptin, waist circumference, fasting insulin and HOMA, whereas adiponectin and HDL-C correlated positively with each other; in this study, plasma omentin levels were compared between thin healthy individuals and obese subjects [21]. Being similar with this negative correlation between omentin and leptin, we determined an inverse relation between omentin and vaspin. So we consider that adipokines may have positive or negative interrelations.

Vitamin D exerts its multifactorial effects via its receptors in various tissues. Emerging evidence suggests that adipose tissue could be a target for vitamin D actions, as the 25-hydroxyvitamin D $1 \alpha$-hydroxylase (CYP27B1) and vitamin D receptor genes are expressed by adipocytes of both rodents and human subjects [8]. In addition, vitamin D receptors found in pancreatic $\beta$-cells launched studies on the possible effects of calcitriol on regulation of insulin production $[2,22]$.

Limited number of total participants may be a limitation factor in our study. It did not include the male subjects, and this may also be considered as a limitation. Vitamin D deficiency is more frequent and more severe in women, and we therefore preferred to include female cases in our study.

\section{Conclusion}

$\nabla$

The results of this study suggested that there was a significant, positive correlation between serum vitamin D levels and vaspin, whereas a significant, negative correlation between vitamin D levels and omentin levels. Further studies on larger series are needed in order to confirm these results.
Disclosure of interest: The authors declare that they have no confilicts of interest concerning this article.

\section{References}

1 Heaney RP. Vitamin D in health and disease. Clin J Am Soc Nephrol 2008; 3: 1535-1541

2 McGill AT, Stewart JM, Lithander FE et al. Relationships of low serum vitamin D3 with anthropometry and markers of the metabolic syndrome and diabetes in overweight and obesity. Nutrition Journal 2008; 7: 1-5

3 Bluher M. Do adipokines link obesity to its related metabolic and cardiovascular diseases? Clin Lipidol 2010; 5: 95-107

4 Bluher M, Rudich A, Kloting $N$ et al. Two patterns of adipokine and other biomarker dynamics in a long-term weight loss intervention. Diabetes Care 2012; 35: 342-349

5 Bays HE. "Sick fat", metabolic disease, and atherosclerosis. Am J Med 2009; 122: 26-37

6 Hida $\mathrm{K}$, Wada J, Eguchi $\mathrm{J}$ et al. Visceral adipose tissue-derived serine protease inhibitor: a unique insulin-sensitizing adipocytokine in obesity. Proc Natl Acad Sci USA 2005; 102: 10610-10615

7 Zhou JY, Chan L, Zhou SW. Omentin. Linking metabolic syndrome and cardiovascular disease. Curr Vasc Pharmacol 2014; 12: 136-143

8 Ding C, Gao D, Wilding J et al. Vitamin D signalling in adipose tissue. British Journal of Nutrition 2012; 108: 1915-1923

9 Bonora E, Targher G, Alberiche $M$ et al. Homeostasis model assessment closely mirrors the glucose clamptechnique in the assessment of insulin sensitivity: studies in subjects withvarious degrees of glucose tolerance and insulin sensitivity. Diabetes Care 2000; 23: 57-63

10 Heidari B, Haji Mirghassemi MB. Seasonal variations in serum vitamin D according to age and sex. Caspian J Intern Med 2012; 3: 535-540

11 Hovsepian S, Amini M, Aminorroaya A et al. Prevalence of vitamin D deficiency among adult population of Isfahan City, Iran. J Health Popul Nutr 2011; 29: 149-155

12 Kiskac M, Zorlu M, Cakirca $M$ et al. Evaluation of the relationship between serum apelin levels and vitamin $D$ and mean platelet volume in diabetic patients. Ann Endocrinol 2014; 75: 200-205

13 Ulutas O, Taskapan H, Taskapan MC et al. Vitamin D deficiency, insulin resistance, serum adipokine, and leptin levels in peritoneal dialysis patients. Int Urol Nephrol 2013; 45: 879-884

14 Maggi S, Siviero P, Brocco E et al. Vitamin D deficiency, serum leptin and osteoprotegerin levels in older diabetic patients: an input to new research avenues. Acta Diabetol 2014; 51: 461-469

15 Gannagé-Yared $M H$, Chedid R, Khalife $S$ et al. Vitamin D in relation to metabolic risk factors, insülin sensitivity and adiponectin in a young middle-eastern population. Eur J Endocrinol 2009; 160: 965-971

16 Nimitphong $H$, Chanprasertyothin S, Jongjaroenprasert $W$ et al. The association between vitamin D status and circulating adiponectin independent of adiposity in subjects with abnormal glucose tolerance. Endocrine 2009; 36: 205-210

17 Shimada K, Miyazaki T, Daida H. Adiponectin and atherosclerotic disease. Clin Chim Acta 2004; 344: 1-12

18 Tschritter O, Fritsche A, Thamer C et al. Plasma adiponectin concentrations predict insulin sensitivity of both glucose and lipid metabolism. Diabetes 2003; 52: 239-243

19 Lee S, Lee DK, Choi E et al. Identification of a functional vitamin D response element in the murine Insig- 2 promoter and its potential role in the differentiation of 3T3-L1 preadipocytes. Mol Endocrinol 2005; 19: 399-408

20 Kamei Y, Kawada T, Kazuki R et al. Vitamin D receptor gene expression is up-regulated by 1,25-dihydroxyvitamin D3 in 3T3-L1 preadipocytes. Biochem Biophys Res Commun 1993; 193: 948-955

21 Souza Batista CM, Yang RZ, Lee MJ et al. Omentin plasma levels and gene expression are decreased in obesity. Diabetes 2007; 56: 1655-1661

22 Pinelli N, Jaber L, Brown $M$ et al. Serum 25-hydroxy vitamin D and insulin resistentance, metabolic syndrome, and glucose intolerance among Arab Americancans. Diabetes Care 2010; 6: 1371-1375 